\title{
Um ensaio sobre o culto ao corpo na contemporaneidade
}

\section{An essay on the cult of the body in contemporary}

\section{J urema Barros Dantas*}

Universidade Veiga de Almeida - UVA, Rio de Janeiro, Rio de Janeiro, Brasil

\begin{abstract}
RESUMO
Pensar o modo como a valorização do corpo vem se tornando o imperativo do viver contemporâneo parece ser uma questão fundamental para o campo da Psicologia. O culto ao corpo se mostra como característica de nossa época e encontra-se assentado na busca diária por um corpo perfeito capaz de superar qualquer problema e corresponder qualquer expectativa. Visto pelos meios de comunicação como algo que pode ser manipulado ou modificado, o corpo vem se tornando pólo dos mais profundos desejos e um grande objeto de investimento. Discutir a relação que estamos construindo com o nosso corpo na atualidade é a preocupação deste artigo.
\end{abstract}

Palavras-chave: Corpo; Beleza; Perfeição; Atualidade.

\begin{abstract}
Think how the appreciation of the body has become the imperative of contemporary living seems to be a key issue for the field of psychology. The cult of the body proves to be typical of our time and is seated in the daily quest for a perfect body can overcome any problem and meet any expectations. Seen by the media as something that can be manipulated or modified, the body has become the pole of the deepest desires and a great object of investment. Discuss the relationship we are building with our body today is the concern of this article.
\end{abstract}

Keywords: Body; Beauty; Perfection; Nowadays.

\section{Introdução}

No fundamento de qualquer prática social, como mediador privilegiado e pivô da presença humana, o corpo está no cruzamento de todas as instâncias da cultura, o ponto de atribuição por excelência do campo simbólico.

(LE BRETON, 2003, p. 31)

Na sociedade contemporânea, o corpo tem se configurado cada vez mais como um dos principais espaços simbólicos na construção dos modos de subjetividade de nossa época. Vários autores têm apontado a dimensão que o corpo passou a ocupar em nossa sociedade. 
Colocar o corpo em cena não é algo novo. Esta temática vem aparecendo em inúmeras publicações, em diferentes áreas do conhecimento, nos últimos anos. Neste trabalho queremos convidar o leitor a pensar o corpo contextualizado historicamente, pois nossa história é tão múltipla quanto os corpos que dela fazem parte.

São variados os panoramas do corpo na história. Ao longo dos anos fomos tecendo diferentes formas de pensar corpo bem como fomos construindo diferentes formas de nos relacionar com ele. Isto porque as questões que envolvem o corpo são susceptíveis a qualquer influência social, cultural, política e científica. Pensar o corpo mergulhado num contexto histórico implica um reconhecimento do mesmo para além de uma demarcação biológica pautada em um funcionamento orgânico. Um corpo que não pode ser aprisionado ou compreendido apenas pela delimitação da epiderme e sua rica fisiologia.

Sabemos que, outrora, a nossa sociedade influenciada pela medicina dos humores acreditava que os mesmos constituíam os corpos vivos e toda natureza. Sabemos também que houve um avanço fenomenal no campo médico com o ato da primeira dissecação corporal, ainda no século XVI, onde nos permitimos ousar em descobrir possíveis causas das mazelas que assolavam a população da época. Desde então o saber médico, pautado em ciência e tecnologia, se revigora na tentativa de resolver os diversos problemas da humanidade.

Neste cenário da busca pelo entendimento e possível controle do corpo, percebemos que desde a renascença o mesmo vem sendo progressivamente desvelado. O corpo, notoriamente, percorre a história da ciência e da filosofia. Mostra-se um conceito aberto, polêmico e, por vezes, multifacetado. De Platão a Bérgson, passando por Descartes, Espinosa, Merleau-Ponty, Freud e Marx, a definição de corpo sempre pareceu um problema. Quase todos conhecem a visão dualista de Descartes, que define o corpo como uma substância extensa em oposição à substância pensante. Massa composta de osso e carne, o corpo é para Descartes, "uma mecânica articulada comparada a um relógio composto de arruelas e contrapesos" (NOVAES, 2003, p. 9). Podemos perceber que seguindo este modo de compreensão, sobretudo no início da modernidade, o corpo foi facilmente associado a uma maquina. O corpo foi pensado como um mecanismo elaborado por determinados princípios que alimentam as engrenagens desta máquina promovendo o seu bom funcionamento.

Ao ser tornado uma máquina, ou melhor, um objeto, foi possível controlar, dividir, reconstruir, estudar, manipular e prever o funcionamento do corpo. Com isto nos aproximamos cada vez mais das supostas promessas do saber médico. Um saber que pretende decifrar esta máquina da forma mais apropriada. Nosso apego às possíveis descobertas acerca do corpo se fortificam diariamente. Parece-nos que cabe ao cenário contemporâneo, mais precisamente à 
medicina, engrandecida de conhecimento e tecnologia, atender as nossas necessidades, anseios e mais íntimos desejos. Descobrir o funcionamento e o provável domínio sobre os fenômenos do corpo, sobretudo, da vida e da morte se revelam como ícones do viver moderno. Percebemos que a objetividade no conhecimento é condição para a eficácia na ação, mas ação num sentido muito específico, que é o de produção ou fabricação. Falamos de um corpo que pode ser modificado a partir das intervenções da ciência presentificadas nas ações médicas.

Este cenário atual que engessa o corpo num processo de possível ajuste, reparo e adaptação é o nosso interlocutor ao longo deste texto. Pensaremos o corpo historicamente construído conforme os sonhos e receios de nossa época e cultura. Talvez em nossa época se desvele uma aparente ambição de dominar o corpo e mantê-lo sob controle seja em busca da saúde, da beleza ou, até mesmo, da juventude. Isto porque "depois de muitas experiências na anatomia, os séculos XIX e XX são dominados pela teoria celular na biologia e pela patologia celular na medicina. Por fim, a ciência decifra o código genético, e o século XXI entre de maneira irreversível nas biotecnologias". (NOVAES, 2003, p. 8). Neste cenário de possível dominação e controle sobre o corpo, as biotecnologias se tornam possíveis aliadas no que se refere à difusão e realização de uma enorme diversidade de estratégias de intervenção no corpo. Vetores tecnológicos direcionados para o corpo mais precisamente para o seu desenvolvimento e funcionamento. Incidindo sobre o corpo, este horizonte tecnológico nos convida a uma reflexão sobre o culto ao corpo na atualidade ressaltando a intrínseca relação entre corpo, tecnologia, saúde e beleza.

\section{Corpo, saúde e beleza: enlaces do culto ao corpo na atualidade}

Neste contexto onde o corpo se torna polo de preocupação e investimento nos parece que a questão do culto ao corpo se mostra como um tema fundamental de discussão para o campo da Psicologia. Passaram-se os anos e a inserção das tecnologias no nosso dia-a-dia fez com que a estética e a construção do corpo mudassem consideravelmente. A relação com nosso corpo parece estar sendo radicalmente modificada pelo fácil acesso a diversos recursos ligados à boa forma, criando certa exaltação e supervalorização do corpo.

O indivíduo parece ser responsável por sua aparência física por meio das várias formas de construções corporais hoje presentes no mercado - como as dietas, os exercícios físicos, os variados tratamentos de beleza e as cirurgias plásticas. E, assim, o corpo atual, ou seja, aquele que se encontra em consonância com os 
padrões de beleza contemporâneos que associam juventude, beleza e saúde apresenta-se como um valor fundamental na sociedade ocidental.

Logo, partimos da ideia de que o culto ao corpo apresenta-se como um possível instrumento de adequação a valores idealizados, ligados à estética, ao comportamento e aos estados de ânimo e, por fim, como meio eficiente de nos conduzir a tão sonhada felicidade. Em outras palavras, o culto ao corpo está sendo entendido neste trabalho como um modo de relação dos indivíduos com seus corpos baseada numa preocupação exacerbada em modelar e aproximar este corpo do ideal de beleza estabelecido. Na sociedade contemporânea, o enquadramento nos padrões deste culto ao corpo tem encorajado a procura por diversos procedimentos médicos como solução rápida para algumas insatisfações. Além da supervalorização da juventude com um bem em si mesmo, acrescentou-se a ideologia de um corpo não só jovem, mas também portador de medidas ideais. Um corpo magro, belo e jovem virou um mandamento ligado à idéia de sucesso e felicidade de nossa época. O suposto sacrifício exigido para modelar o corpo é compensado idealmente pela crença de um sucesso futuro.

Por que estamos tão preocupados com as curvas e as formas de nosso corpo? Por que a cada dia aumenta o número de indivíduos que buscam alternativas visando o emagrecimento? Por que furiosamente buscamos um elixir da juventude e da beleza? Enfim, o que está tornando o corpo um lugar de destaque na sociedade contemporânea? Na tentativa de compreender tal situação, entenderemos o nosso contexto sócio-histórico atual como cenário que potencializa a crença no corpo ideal ainda que seja por meio das mais diversas tecnologias ávidas em realizar todo e qualquer sonho. Os limites do corpo são extrapolados, muitas vezes com o auxílio da tecnologia, no esforço imitativo de modelos quase sempre irreais e inatingíveis, muitos criados e ajustados por diversas técnicas, por aparatos medicamentosos ou procedimentos cirúrgicos. O corpo, na atualidade, parece assim se apresentar como uma síntese de desejo, ciência e tecnologia, a serviço do chamado bem-estar. Isto porque a tecnologia desenvolvida pela racionalidade científica e os valores e sentidos produzidos no mundo social agora constroem corpo. A indústria do culto ao corpo orienta perfeitamente o que devemos fazer para tornar o nosso corpo um modelo perfeito que obedece ao que se espera no mundo social. Esta indústria possui todo um aparato tecnológico adequado a cada situação, corpo ou bolso. Esta indústria opera a partir de uma lógica que transforma tudo em algo mensurável, pragmático e utilitário a fim de buscar uma resposta para a insatisfação crescente com relação ao corpo. O corpo contemporâneo precisa ser melhorado, ampliado, ajustado, modificado e, até mesmo, criado. Precisa de próteses químicas e de procedimentos de toda ordem que o tornem forte, belo e adequado 
ao cenário atual. O corpo parece ser um molde que se adapta às significações sociais. Por vezes parece ser um rascunho que pode ser refeito ou aperfeiçoado de acordo com o desejo e o bolso do indivíduo. Nosso corpo parece estar se tornando um grande laboratório onde se redesenha a própria condição humana. Redesenha o cuidado que devemos ter com o nosso corpo na tentativa de ampliar seus limites.

As globalizadas sociedades de consumo parecem atribuir aos indivíduos a responsabilidade pelo cuidado e pela plasticidade de seu corpo. Todas as condições técnicas necessárias são oferecidas para que possamos administrar nosso corpo com as opções disponíveis no mercado. Com um pouco de esforço e trabalho físico, homens e mulheres são diariamente persuadidos a alcançar a aparência desejada, mesmo que para isso sejam necessários exercícios intensos, cirurgias plásticas e dietas radicais - como pregam os diversos meios de comunicação vigentes. $E$, assim, o corpo se configura quase como um detalhe biológico tecnicamente controlável. Um horizonte de controle que nos oferece a idéia de uma possível mudança corporal de forma rápida e sem dor. Oferece-nos a idéia de que precisamos de próteses químicas, mecânicas e medicamentosas para prosseguir em nosso viver cotidiano.

Ainda que estes cuidados despendidos ao corpo não seja algo novo, foi segundo Sant'Anna (2001), a partir dos meados do século XX que a atenção e a dedicação ao corpo se tornaram um direito e um dever incontestáveis, misturando-se aos preceitos de higiene e às novas necessidades de conforto. O século XX parece ter sido marcado pela valorização da aparência e cuidar do corpo desde então passou a ser uma necessidade. Uma necessidade alimentada diariamente com o surgimento sofisticado dos produtos light, das mais modernas intervenções cirúrgicas ou as gloriosas e diversificadas atividades físicas. Podemos ainda mencionar a microbiologia, a robótica, a farmacologia e a genética como férteis promessas de um corpo perfeito.

Além dos cuidados com o corpo em nome da saúde, o que se busca hoje com esse culto exacerbado é, no limite, o ajuste ao modelo de juventude e felicidade permanente que encanta a sociedade contemporânea. Somos afetados pela difusão de informações de que podemos e devemos encontrar as mais recentes soluções para todos os males do corpo, vendidas facilmente nas drogarias ou parceladas em infinitas prestações de uma cirurgia estética. Os discursos sobre a saúde e a estética parecem indissociáveis e convergem para o mesmo imperativo: o cuidado com o corpo. Tal cuidado vem se tornando demasiado, quase uma obrigação diária, gerando por vezes sentimento de culpa naqueles que não podem realizá-lo. Em nosso dia-a-dia surgem obrigações com o corpo quase religiosas, rituais que devem ser seguidos a todo custo em prol de um melhor resultado. Os 
cuidados com o corpo e a intensificação das sensações corporais se mostram como questões centrais da vida cotidiana.

\title{
3 Os meios de comunicação e o culto ao corpo: um campo de influência
}

Os manuais de autoajuda, as revistas especializadas, a publicidade em geral levam os indivíduos a acreditarem que toda e qualquer imperfeição ou defeito é fruto de negligência pessoal e falta de cuidado de si. Com bastante disciplina e força de vontade, seguindo os conselhos dos experts, qualquer um pode atingir uma aparência próxima ou similar ao padrão de beleza vigente. Assistimos constantemente a busca obstinada pelas formas retilíneas e esbeltas.

\begin{abstract}
A imagem da juventude, associada ao corpo perfeito e ideal - que envolve as noções de saúde, vitalidade, dinamismo e, acima de tudo, beleza - atravessa, contemporaneamente, os diferentes gêneros, faixas etárias e classes sociais, compondo de maneira diferenciada, diversos estilos de vida. E a fábrica de imagens - cinema, TV, publicidade - ao lado da imprensa escrita, tem, certamente, contribuído para isso (CASTRO, 2007, p. 112).
\end{abstract}

Diante dos apelos dos meios de comunicação, que muitas vezes afirmam ser fácil obter formas belas e torneadas, o corpo se fragiliza afinal, silicones, esteróides, medicamentos, cirurgia a laser, botox e alimentos transgênicos são apenas alguns dos muitos elementos que proporcionam ao indivíduo opções eficazes na conquista desse corpo esteticamente perfeito. Para Castro (2007, p. 28): "a possibilidade de esculpir-se ou de desenhar seu próprio corpo é algo que propicia a cada um estar o mais próximo possível de um padrão de beleza estabelecido globalmente; afinal, as medidas do mercado da moda são internacionais".

Esculpir, modelar e transformar são verbos muito presentes nos discursos diários sobre o corpo e verbos fortemente endossados pelo saber médico. Estamos falando de uma tecnologia a serviço de uma suposta melhoria no corpo. Parece que nossa relação com o corpo encontra-se atravessada pelo nosso momento histórico e por um olhar de intervenção médico que nos diz exatamente como enfrentar e alterar as mudanças do nosso corpo. Situações antes consideradas normais de serem enfrentadas durante a vida estão sendo majoritariamente tratadas e solucionadas pela medicina. Buscamos os últimos tratamentos de emagrecimento, o novo ácido capaz de retardar o envelhecimento, a cirurgia capaz de transformar o corpo em obra de arte. Obra de arte encontrada em revistas e passarelas da moda. Medicalizamos e tratamos o corpo por uma não aceitação 
do mesmo enquanto um processo natural de contínua mudança. Nos rendemos aos modismos tornando o corpo objeto e esquecemos seu caráter temporal e histórico. Featherstone (1995) já mostrava o quanto a experiência estética dominava o cotidiano dos indivíduos, conferindo-Ihes sentido e possibilitando a auto-expressão e a construção de um estilo de vida.

Descoberto pelo olhar contemporâneo, o corpo vem sendo objeto de uma incansável interrogação que se estende das páginas dos jornais aos salões dos museus, dos outdoors das avenidas às salas e cinema, dos programas de televisão aos debates acadêmicos. Percebemos que manuais de dietas, prometendo regimes cada vez mais infalíveis, para produzir corpos livres de gordura, esbeltos e graciosos, são tipos de publicações que aparecem invariavelmente entre os livros ou revistas mais vendidos. De fato, o mundo globalizado parece ter colocado o corpo na ordem do dia. Contudo, isso não resultou necessariamente em produção de conhecimento. E, por isso mesmo, a moda do culto ao corpo demanda reflexão. Uma reflexão onde o ponto de partida é dado pela ideia de que a cultura apropria-se do corpo biológico para redefini-lo em termos sociais e, assim, transformá-lo em corpo "cultural". Castro (2005) afirma que, no mundo humano, a experiência corporal é invariavelmente atravessada pela vivência cultural, tornando-se uma fonte de símbolos, de construção de identidades e de estilos de vida. Podemos ousar em dizer que o corpo é sempre território da cultura. A nossa cultura contemporânea marcada pela égide do consumo, do individualismo e hedonismo parecem entender corpo como sinônimo da boa forma.

\begin{abstract}
A boa forma passa a ser considerada uma espécie de melhor parte do indivíduo e que, por isso mesmo, tem o direito e o dever de passar por todos os lugares e experimentar diferentes acontecimentos. Mas aquilo que ainda não é boa forma e que o indivíduo considera "apenas" o seu corpo, torna-se uma espécie de mala por vezes incomodamente pesada, que ele necessita carregar, embora muitas vezes ele queira escondê-la, eliminá-la ou aposentá-la. Durante séculos o corpo foi considerado o espelho da alma. Agora ele é chamado a ocupar o seu lugar, mas sob a condição de se converter totalmente em boa forma (SANT'ANNA, 2001, p. 108).
\end{abstract}

É notório o quanto o conceito de boa forma é confundido com o significado de saúde. Ambos os conceitos referem-se às condições do corpo, mas o primeiro confere uma certificação de pertencimento e inclusão. Como nos diz Bauman (2007), a boa forma refere-se à qualidade do corpo de produzir prazeres que será capaz de usufruir: corpo bem-disposto, hábil, eficiente e grato dos prazeres conquistados. O problema encontra-se no fato de que, colocar o 
corpo com demasiada frequência no estado de boa forma, choca-se com o propósito que esse estado deveria produzir.

\section{A busca pela boa forma: o vício do momento}

Na busca pela boa forma, diferentemente do que ocorre com a saúde, não há um ponto em que se possa dizer agora que alcancei, posso parar e manter o que conquistei. "A luta pela boa forma é uma compulsão que logo se transforma em vício. Cada dose precisa ser seguida de outra maior" (BAUMAN, 2007, p. 123). A procura pela boa forma desconhece limites e refere-se a prazeres sequer imaginados, mas que devem ser alcançados, cedo ou tarde. Não importa a excelente forma que o corpo esteja neste momento - sempre será possível melhorar. Há sempre uma dose irritante de má forma a ser aperfeiçoada. Dessa maneira, cada alvo não passa apenas de mais um degrau em uma longa e sucessiva escada.

A busca pela boa forma demanda de uma pessoa um constante movimento. Bem como instiga e valoriza nossa flexibilidade e nossa capacidade de estar sempre apto para novas mudanças e para todos os formatos possíveis de remodelagem. Reformar o corpo, de modo obsessivo e devotado, parece ser tanto um dever quanto uma necessidade.

Entender o modo pelo qual a sociedade compreende e se relaciona com o corpo é uma questão fundamental na medida em que Bauman (2007) propõe que devemos conceber o corpo como potencialidade elaborada pela cultura e desenvolvida nas relações sociais. Torna-se válido reconhecer que, na maior parte das vezes, estabelecemos com nosso corpo uma relação estética subordinada a padrões de beleza e saúde, evidencia o que o corpo se mostra como fenômeno social e cultural ou, como nos diz Le Breton (2006), como motivo simbólico, objeto de representações e imaginários. O mesmo autor sugere que as ações que tecem a trama da vida cotidiana, das mais fúteis ou menos concretas até aquelas que ocorrem na cena pública, envolvem a mediação da corporeidade. O corpo é, por assim dizer, um vetor semântico pelo qual a evidência da relação com o mundo é construída. O corpo constitui o âmago da relação do homem com o mundo. Do corpo nascem e se propagam as significações que fundamentam a existência individual e coletiva.

Pela corporeidade, o homem faz do mundo a extensão de sua experiência, transformá-lo em tramas familiares e coerentes, disponíveis à ação e permeáveis à compreensão. Emissor ou receptor, o corpo produz sentidos continuamente e assim insere o homem, de forma ativa, no interior de dado espaço social e cultural (LE BRETON, 2006, p. 08). 
O corpo é o centro do cotidiano de cada pessoa, em suas aspirações de saúde perfeita, juventude eterna e beleza ideal. Além disso, o corpo é palco de paradoxos e conflitos, pois o mesmo corpo que busca sua singularidade é o que tenta negar a diferença e a alteridade. Busca-se no corpo a felicidade plena.

Os indivíduos lançam mão de recursos para se aproximarem do ideal de estética corporal que a sociedade define, destacando, dissimulando ou atenuando particularidades de sua aparência: dietas, exercícios físicos, operações cirúrgicas. Acreditam que assim estão incrementando a vitalidade de sua constituição orgânica e social. O culto ao corpo é quase uma técnica de sobrevivência da sociedade atual, uma vez que pretende garantir as melhores soluções para as situações presentes na vida cotidiana. Castro (2007, p. 30) defende que "o culto ao corpo é, hoje, preocupação geral, que atravessa todos os setores, classes sociais e faixas etárias, apoiado no discurso da estética e da preocupação com a saúde".

No entanto, ao mesmo tempo em que há essa busca incessante para adquirir um corpo individualizado, o indivíduo acaba por se perder nas exigências do social. Trata-se da busca por um ideal inatingível, já que as imagens veiculadas são tão perfeitas que parecem não humanas; assim essa procura por esse ideal leva o sujeito à insatisfação, devido à impossibilidade de se atingir tal padrão. Não atingir o modelo remete o indivíduo a um sentimento de impotência frente ao próprio corpo.

O sentimento de impotência e a busca obstinada em corresponder aos padrões facilmente vendidos pelo nosso horizonte histórico parecem também ter se tornado uma fonte de lucros tendo em vista a ansiedade em torno dos cuidados com o corpo. Para a lógica do mercado a promessa de reduzir ou eliminar essa ansiedade é amplamente sedutora e então abraçada. Contudo, tal ansiedade deve ser constantemente reforçada pelo mercado, para que a mais durável demanda do consumo nunca sofra uma escassez. Em suma, os mercados de consumo estimulam, reforçam e se alimentam da mesma ansiedade que prometem reduzir com seus produtos. Compartilhamos com Bauman (2007) a afirmação de que, ao contrário da demanda do consumidor de satisfação dos desejos, o consumismo refere-se à incitação dos mesmos desejos, sempre renováveis. Todos os esforços são para que o ciclo de desejos gire mais depressa.

Pensar essas significações na atualidade e suas relações com o corpo nos parece ser os pontos que dão concretude ao tema que estamos abordando. A crise de significação e de valores que atravessa a atualidade, a procura tortuosa e incansável por soluções imediatas e o modo com nos relacionamos com nossa finitude, parecem colocar o corpo, num lugar privilegiado de contato com o mundo, sob a luz dos holofotes. O corpo encontra-se numa genuína dialética com o social, 
sendo objeto de investimento coletivo, suporte de ações e significações, motivo de alegria e desilusões pelas práticas e discursos que suscita.

\section{Corpo e contemporaneidade}

O homem quer viver mergulhado em satisfações imediatas, buscar sensações que o façam esquecer-se das preocupações e ameaças futuras, estabelecer sua organização de vida no presente, vivendo o momento atual e nada mais. Assim, o passado e o futuro não têm espaços na organização do seu cotidiano. Sendo o corpo o espaço onde se situa toda a ambiguidade existencial, a busca do corpo perfeito é tomada como tentativa de negar o futuro, pois é através do corpo que o tempo deixa sua marca. Concordamos com Castro (2007, p. 24) quando ela afirma que: “a preocupação com o corpo esbelto sinônimo de corpo saudável - na contemporaneidade, pode ser compreendida como algo que diz respeito à condição do indivíduo na modernidade".

Neste cenário atual, o corpo torna-se facilmente lugar de concretização do bem-estar e do parecer bem através da forma e da manutenção da juventude. Numa sociedade onde ser feliz muitas vezes está vinculado à aparência, ao status e ao sentir bem o tempo todo, o corpo torna-se objeto de constante investimento e preocupação. Atualmente, esse culto ao corpo se alimenta de uma lógica onde "ser belo é aproximar-se de um ideal, sempre determinado de modo universal, distinto do que é cada corpo, enquanto este, por sua vez, é considerado um ente particular e local" (SANT'ANNA, 2001, p. 108).

De acordo com a lógica do culto ao corpo, a gordura corporal representa o pesadelo realizado. O ganho de peso e centímetros na cintura é um alerta que os esforços nada estão valendo. Bauman (2007) escolhe termos referentes à guerra para ressaltar o fracasso na tentativa constante de perder peso quando diz que as forças inimigas invadem o território defendido, e pior, ali se estabelecem, agora exercendo a administração das terras dominadas. Observamos, assim, um grande grito de guerra contra a gordura, uma nova versão de uma luta em que a última batalha não está à vista e não há perspectiva de vitória.

O indivíduo contemporâneo parece considerar o corpo o terreno sólido em que realiza esses ideais pregados pela sociedade contemporânea. $\mathrm{O}$ indivíduo parece manter com o corpo, visto como seu melhor trunfo, uma relação de terna proteção e de esgaçamento de seus limites, da qual retira um benefício narcíseo e social, pois sabe que na maior parte das vezes, é a partir dele que são estabelecidos os julgamentos de felicidade, saúde e beleza. Pensar a 
obsessão atual pela construção da aparência como espécie de resposta à instabilidade, fragmentação e efemeridade que marcam a vida social nos ajuda a compreender a centralidade assumida pelo culto ao corpo na cultura contemporânea.

Mergulhados no consumo entendemos o corpo como mais uma mercadoria disponível para uso ou para compra no mercado aberto. Neste campo de manipulação de objetos e símbolos que caracteriza a nossa cultura do consumo, J. Baudrillard faz do corpo o mais belo objeto do investimento individual e social. Compartilhando dessas considerações, G. Lipovestky, enquanto analista meticuloso de nosso momento histórico apresenta que a personificação do corpo exige o imperativo da juventude, a luta contra a adversidade temporal, o combate para que nossa identidade se conserve sem hiato nem pane e, simultaneamente, o narcisismo cumpre uma missão de normalização do corpo. Parece-nos que o corpo hoje se impõe como lugar de predileção do discurso social.

Podemos compreender a importância do corpo no sonho de tornar visível o belo, o bem-estar e a felicidade. O corpo parece, então, ter se tornado uma espécie de íntimo companheiro, um verdadeiro parceiro daquele de quem se exige a melhor apresentação, as sensações mais originais, a boa resistência, a juventude eterna e o corpo esbelto pela magreza. O indivíduo é convidado a descobrir o corpo como um grande potencial, onde é necessário manter certa sedução e explorar todos os limites possíveis.

O corpo é território de onde emana sensação e sedução, um território a ser explorado na procura de sensações inéditas ou prazeres exclusivos a serem capturados. $E$, assim, encontramos o parceiro compreensivo e cúmplice que faltava do nosso lado. Cúmplice na conquista do momento perfeito, do estado almejado de êxtase ou das tão sonhadas curvas femininas. Para tudo isso foi necessário:

[...] transformar o corpo num território privilegiado de
experimentações sensíveis, algo que possui uma certa
inteligência que não se concentra apenas no cérebro. Foi
preciso, ainda, libertá-lo de tradições e moralismos
seculares, fornecer-lhe um status de prestígio, um lugar
radioso, como se ele fosse uma alma. Desde então foi fácil
considerá-lo uma instigante fronteira a ser vencida,
explorada e controlada (SANT'ANNA, 2001, p. 70).

Nesta lógica dos dias atuais o corpo transforma-se em objeto a ser moldado, modificado, modulado, conforme o gosto do dia. O corpo é apresentado e tecnicamente testado como ferramenta indispensável na realização dos ideais da aparência, da ostentação, do bem-estar e da felicidade na atualidade. Trata-se de experimentar, à custa do corpo, a capacidade íntima em corresponder aos ideais de nossa sociedade. 


\section{Considerações Finais}

A publicidade e o consumo parecem ser aspectos estruturantes da prática do culto ao corpo. A primeira, por tornar presente diariamente na vida dos indivíduos temáticas acerca do corpo, seja pelas mais avançadas tecnologias ou pelo mais recente chá descoberto, ditando cotidianamente estilos e tendências. A segunda, pelo horizonte que torna o corpo um objeto passível de consumo. A lógica do consumo se faz imperiosa nos modos de relação que estabelecemos com 0 nosso corpo. Somos permeados pela crença de que podemos consumir desde receitas até próteses perfeitas. O nosso corpo tornou-se extensão do mercado e os produtos de beleza suas valiosas mercadorias.

Em nosso horizonte histórico percebemos o culto exacerbado do corpo e a perseguição de modelos estéticos estabelecidos socialmente. Falamos de um ideal vinculado pelo social que vende a saúde e a beleza como conjunto de curvas perfeitas, pela sedosa, cabelos lisos e, sobretudo, a magreza. O corpo como mensageiro da saúde e da beleza torna-se um imperativo tão poderoso que conduz à idéia de obrigação. Ser feliz e pleno na atualidade corresponde a conquista de medidas perfeitas, bem como a pele e o cabelo mais reluzente. O corpo ganhou uma posição de valor supremo, seu bemestar parece ser um grande objetivo de qualquer busca existencial na atualidade.

As representações sociais do corpo e de sua boa forma aparecem como elementos que reforçam a autoestima e dependem em grande parte da força de vontade pois, quem quer pode ter um corpo magro,belo e saudável. A aparência de um corpo bem definido e torneado indicaria saúde, revelando o poder que a exaltação e exibição do corpo assumiram no mundo contemporâneo. A mídia de um modo geral tornou-se, assim, uma importante forma de divulgação e capitalização do que estamos chamando de culto ao corpo.

Entendemos que os cuidados com o corpo são importantes e essenciais não apenas no que se refere à saúde, mas também ao que se refere ao viver em sociedade. O problema reside na propagação de um ideal inatingível, na culpabilização do indivíduo por não atingir este ideal, no fato de tornamos as mudanças naturais do corpo, objetos estéticos da medicina, o fato de não entendermos ou ouvirmos as verdadeiras necessidades corporais que temos. Como bem nos diz Sant'Anna (2001, p. 79): "não se trata, portanto, de negar os avanços da tecnociência, nem de condená-la em bloco. Mas de reconhecer que o corpo não cessa de ser redescoberto, ao mesmo tempo em que nunca é totalmente revelado".

Em nossa sociedade moderna, elaboramos e desenvolvemos o corpo como potencialidade, uma vez que agora temos meios de exercer 
sobre os corpos um grau de controle sem precedentes. Entretanto, surge a pergunta: será que esta nova situação realmente alargou a liberdade individual, abrindo a cada um de nós um leque mais amplo de escolhas? Será que esse grau de controle não nos deixou apenas mais inseguros sobre os critérios de avaliação dos corpos e sobre os passos necessários para aproximá-los de como deveriam ser? Parecenos que a impressão de liberdade ampliada se tornou apenas um novo conjunto de necessidades não menos opressivas, e as possibilidades de escolhas tornaram-se obrigatórias e inevitáveis, não podendo assim ser negligenciadas e tão pouco recusadas.

Nosso convite à reflexão se refere ao fato de creditarmos quase cegamente nossas alegrias, nosso bem-estar e, acima de tudo, nossa felicidade, aos produtos de beleza, aos ácidos, aos procedimentos estéticos e porque não dizer, aos medicamentos de todo gênero. Enquadrar-se em padrões externos é uma escolha a ser feita, e como em toda escolha, há uma responsabilidade implicada. O culto ao corpo é uma obrigação na atualidade, será que nossa correspondência à esses padrões quase universais também é?

De fato o corpo tornou-se, facilmente, fonte de intervenção, informação e pesquisa. O discurso científico nos invade com suas revolucionárias ferramentas estatísticas responsáveis por definir as possibilidades de adoecimento, felicidade e mortalidade dos indivíduos. Que o corpo roubou a cena no contexto atual isto é um fato. Que os cuidados com ele se tornaram quase uma imposição isto é notório.

Por ele fazemos qualquer sacrifício: regimes rigorosos, controle de peso, pílulas, ginástica, cirurgia. Dele esperamos prazeres, alegrias e sensações ilimitadas. Essas discussões podem se mostrar como uma simples constatação dos atravessamentos vividos em nossa época ou pode nos levar a compor outras perspectivas sobre o corpo. Um corpo que não se esgota numa compreensão biológica. Um corpo que invariavelmente está atravessado por toda uma vivência cultural e expressa os nossos modos de ser e estar no contemporâneo.

Queremos inquietar o leitor para o modo de relação que estamos construindo com nosso corpo, despertando um olhar que não ambiciona oferecer uma resposta absoluta sobre o corpo, mas sim um olhar que se mostre como um feixe de caminhos. Caminhos questionadores, reflexivos e, até mesmo, transformadores sobre nossas perspectivas sobre a questão do corpo na atualidade.

\section{Referências}

BASTOS, L. A. M. Corpo e subjetividade na medicina. Rio de J aneiro: Editora UFRJ, 2006. 
BAUDRILLARD, J. A sociedade de vonsumo. Lisboa: Edições 70, 1981.

BAUMAN, Z. O mal-estar da pós-modernidade. Rio de Janeiro: J orge Zahar, 2001.

Vida Líquida. Rio de Janeiro: Jorge Zahar, 2007.

CASTRO, A. L. Culto ao corpo e sociedade: mídia, estilos de vida e cultura de consumo. São Paulo: Annablume - FAPESP, 2007.

COBRA, G. O. Corpo e identidade: um estudo funcional da organização biopsíquica da identidade. 1999. 187 f. Dissertação de Mestrado em Psicologia - Programa de Pós Graduação em Psicologia da, Pontifícia Universidade Católica do Rio de Janeiro, Rio de Janeiro, 1999.

DUNLEY, G. A festa tecnológica: o trágico e a crítica da cultura informacional. São Paulo: Editora Escuta, 2005.

FEATHERSTONE, M. Cultura de consumo e pós-modernismo. São Paulo: Studio Nobel, 1995.

LE BRETON, D. Adeus ao corpo: antropologia e sociedade. Campinas: Editora Papirus, 2003.

A Sociologia do corpo. Petrópolis: Vozes, 2006.

LIPOVETSKY, G. Os tempos hipermodernos. São Paulo: Editora Barcarolla, 2004.

NOVAES, A. (Org.). O homem-máquina: a ciência manipula o corpo. São Paulo: Companhia das Letras, 2003.

RODRIGUES, J. C. O tabu do corpo. Rio de Janeiro: Achiamé, 1979.

ROMERO, E. As dimensões da vida humana: existência e experiência. São José dos Campos: Novos Horizontes, 1998.

SANT'ANNA, D. B. Corpos de passagem: ensaios sobre a subjetividade contemporânea. São Paulo: Estação Liberdade, 2001.

SCHILDER, P. A imagem do corpo: as energias constitutivas da psique. São Paulo: Martins Fontes, 1999.

SIBILIA, P. O homem pós-orgânico: corpo, subjetividade e tecnologias digitais. Rio de Janeiro: Relume Dumará, 2003.

SLATER, D. Cultura do consumo e modernidade. São Paulo: Nobel, 2002.

\section{Endereço para correspondência}

J urema Barros Dantas

Rua I bituruna no 108, Maracanã, CEP: 20271-020, Rio de Janeiro, RJ, Brasil

Endereço eletrônico: juremadantas@ig.com.br.

Recebido em: 22/03/2010

Reformulado em: 02/06/2010

Aceito para publicação em: 21/06/2010

Acompanhamento do processo editorial: Eleonôra Prestrelo 


\section{Notas}

* Psicóloga, Doutora em Psicologia Social pela Universidade do Estado do Rio de Janeiro- UERJ, Mestre em Psicologia na área de Estudos da Subjetividade pela Universidade Federal Fluminense - UFF, Especialista em Psicologia Clínica e Professora da Universidade Veiga de Almeida, Professora dos Cursos de Especialização do Centro de Estudos de Pessoal do Exército Brasileiro e Professora do Instituto de Fenomenologia do Rio de Janeiro - IFEN/RJ. 